\title{
MEMAHAMI NYANYIAN JEMAAT \\ SEBAGAI SENTRAL MUSIK GEREJA APA DAN BAGAIMANA?
}

\author{
Rohani Siahaan \\ sttjaffraymakassar@yahoo.co.id
}

\section{PENDAHULUAN}

"Nyanyikanlah nyanyian baru bagi Tuhan. Menyanyilah bagi Tuhan, hai segenap bumi!" (Maz96:1).

Nyanyian bagi umat kristiani mempunyai tempat dan nilai yang sama dengan unsur ibadah lainnya yaitu: fokus hanya kepada Allah. Dan sebagai salah satu unsur dalam liturgi ibadah, nyanyian jemaat merupakan apresiasi yang dianggap paling ekspresif dan komunikatif untuk menyatakan imannya, isi hati dan perasaannya. Lewat nyanyian umat mengungkapkan kesiapan menghadap Tuhan, memohon Tuhan hadir, mengaku dosa, memohon pengampunan, mengucap syukur dan memohon berkat Tuhan.

Nyanyian menjadi pelayanan langsung jemaat dalam ibadah, baik selaku pribadi maupun selaku persekutuan. Ia (nyanyian jemaat) menjadi dasar yang paling utama dan dianggap sebagai sentral dari semua musik dan nyanyian lainnya yang ada dalam peribadahan gereja.

Nyanyian jemaat lahir ketika bangsa Israel menemukan identitas mereka sebagai umat yang diselamatkan (Kel.15:1-21) kemudian menjadi awal musik dan nyanyian dikenal sebagai satu cara hidup umat Israel, baik secara agamawi maupun secara duniawi. Tradisi ini berlanjut pada masa Daud dengan penetapan kaum Lewi sebagai pelayan musik ibadah (Bil.8:5-22; I Taw.15:27: II Taw.5:12; Neh.12:44-47); lalu pada masa pelayanan Yesus hingga masa pelayanan Paulus (Mark.14:26; Luk.2:14, 29-32; Yoh.2:13; 7:29; Kis.16:25; Kol.3:16); terus berlanjut ke masa gereja mula-mula, masa reformasi di abad 16-17 hingga ke masa gereja sekarang ini. 


\section{Ciri Nyanyian Jemaat}

Dari sudut ilmu musik nyanyian jemaat digolongkan sebagai community singing yaitu, nyanyian bersama yang dapat dilakukan secara massal. Sifat maupun tujuan nyanyian jemaat adalah menyatukan seluruh umat secara oukumenis dalam ibadah. Isi nyanyian yang terutama bukan perasaan hati, tetapi kekudusan dan ketulusan pribadi dalam mengakui dan menerima pengasihan Allah atas perbuatan-Nya yang besar terhadap dunia ciptaan-Nya.

Pada dasarnya ciri-ciri nyanyian jemaat atau nyanyian gereja tidak berbeda dari musik sekuler pada umumnya, karena nyanyian jemaat dengan ciri dan bentuknya sama dengan nyanyian massal lainnya di luar gereja. Menurut H.A.van Dop dalam bukunya Menggubah Nyanyian Jemaat, tidak ada musik yang khusus gerejawi. ${ }^{1}$ Dasar pernyataan ini karena banyak lagu nasional yang berbunyi sama seperti nyanyian gereja; yang menentukan dalam hal ini adalah fungsi dan tempat maupun waktu di mana nyanyian digunakan sebagai nyanyian orang banyak. Ciri nyanyian yang digolongkan sebagai nyanyian jemaat adalah:

1. Mencerminkan dan mengekspresikan ke-esaan

2. Mudah dinyanyikan secara bersama-sama

3. Bahasanya sederhana dan lagu tidak rumit

4. Isi tidak bersifat pribadi

5. Bentuk syair teratur, dari bait ke bait tidak berubah-ubah

6. Melodi stabil, nada dasar lagu dapat dijangkau seluruh jemaat

\section{Kategori Nyanyian Jemaat}

Berdasarkan tiga aspek yang terkandung pada musik yaitu, musik sebagai ilmu, musik sebagai seni, dan musik sebagai alat komunikasi, pembagian kategori musik dapat dilakukan. Karena dalam setiap aspek ilmu tercakup: melodi, ritme, harmoni, dan syair sebagai faktor internal; pada aspek seni terdapat keindahan yang disertai keterampilan memainkan alat musik maupun menyanyikan lagunya sebagai faktor eksternal; dan pada aspek komunikasi tercipta dari perpaduan ilmu dan seni yang efektif dan seimbang, maka bentuk dan jenis musik pun dapat ditetapkan.

Rasul Paulus dalam suratnya kepada jemaat Kolose secara tegas menuliskan tiga bentuk nyanyian yang penting dan bahkan harus digunakan pada zamannya, bukan hanya sebagai nyanyian tetapi juga sebagai alat untuk mengajar dan menegur, sebagaimana tercatat dalam Kolose 3:16

\footnotetext{
${ }^{1}$ H.A. van Dop, Menggubah Nyanyian Jemaat (Jakarta: BPK Gunung Mulia, 1984), 12.
} 
"Hendaklah perkataan Kristus diam dengan segala kekayaannya di antara kamu, sehingga kamu dengan segala hikmat mengajar dan menegur seorang akan yang lain dan sambil menyanyikan mazmur, dan puji-pujian dan nyanyian

rohani, kamu mengucap syukur kepada Allah di dalam hatimu"

Dengan demikian kategori yang dimaksudkan rasul Paulus adalah nyanyian dengan bentuk Mazmur, Kidung Puji-Pujian, dan Nyanyian Rohani. Dikatakan, jemaat tidak boleh lalai atau mengabaikan salah satu dari ketiga nyanyian itu, pemakaian ketiga nyanyian dalam ibadah harus secara proporsional dan seimbang ${ }^{2}$. Perlu diketahui, meskipun masing-masing nyanyian memiliki bentuk dan tentu saja dengan karakter pun berbeda, namun sebagai nyanyian jemaat ketiganya memiliki fungsi dan peran yang sama ketika dinyanyikan bersama seluruh jemaat yaitu, pertama: menciptakan suasana peribadahan yang sesuai dengan tema dan peruntukannya - untuk pengajaran gereja sesuai kalender gereja - kedua: menjadi respon jemaat terhadap bagianbagian liturgi - misalnya, pembukaan ibadah, votum dan salam, pengakuan dosa, pelayanan firman, pengakuan iman, persembahan syukur, hingga ke pengutusan dan doa berkat - ketiga: untuk mengajarkan doktrin kekristenan dengan pemahaman akan kasih Allah kepada dunia dan pengakuan bahwa Allah berkuasa dalam kehidupan manusia.

\section{Mazmur}

Mazmur merupakan nyanyian tertua dan utama dalam sejarah peradaban musik umat Tuhan. Secara harafiah Mazmur artinya : pujipujian orang Israel; lebih lengkapnya lagi, Mazmur atau mixmour (kata: Ibr.) dan psalmody (kata: Yun.) memberi arti yang sama yaitu nyanyian puji-pujian orang Israel yang dibawakan dengan iringan alat musik. Bentuk penulisan syairnya mengikuti kaidah sastra Ibrani, berbentuk asimetrik, tema umum: kematian dan kelahiran kembali, ucapan syukur. Inti pengajarannya: percaya dan bersandar kepada Allah yang hidup, yang mendengar, dan yang menjawab doa umatNya. Lazimnya dinyanyikan secara unisono (satu suara) dengan gaya responsorial - antiphonal - litanical. Ciri musikalnya: nada-nada kurang melodis, tidak memakai harmoni, notasi tidak memiliki garis birama, dan jumlah suku kata setiap baris tidak sama3. Meskipun Mazmur bukan hanya yang 150 nomor dalam Alkitab, melainkan setiap

\footnotetext{
${ }^{2}$ Lovelace and Rice, Music And Worship In The Church (Abingdon Nasville, 1981).154.

${ }^{3}$ H.A. Van Dop, Menggubah Nyanyian Jemaat, 33-39.
} 
pernyataan puji-pujian yang agung dan mulia yang tercatat dalam seluruh kitab Perjanjian Lama, tetapi memang dari semula Mazmur yang diperuntukkan sebagai nyanyian umat, dan kemudian dalam penggunaannya dinyatakan sebagai nyanyian gereja yang dianggap sangat oukumenis dan membumi dari masa Alkitab hingga masa kini. ${ }^{4}$

2. Kidung Puji-Pujian

Kidung Puji-Pujian lebih dikenal sebagai himne dengan bentuk syair mengikuti kaidah sastra Yunani yang berbait/strofe. Mulai muncul pada awal kekristenan mula-mula sebagai alternatif atas keterbatasan Mazmur dalam mengungkap pengalaman iman tentang keselamatan. Tema umum: penyembahan atau memuliakan Allah Tri Tunggal. Inti pengajaran bersifat objektif - vertical - dan sangat liturgis. Pesan atau isi himne berkembang dari bait ke bait tanpa refrein; dengan syair yang berbicara tentang Allah, Yesus Kristus, Roh Kudus, Allah Tri Tunggal, kebenaran Firman Tuhan, alam serta lingkungan maupun, masalahmasalah sosial. Notasi atau nada-nada biasanya memiliki nilai yang sering sama, sangat sedikit menggunakan nada yang bernilai 1/8 (seperdelapan) atau 1/16 (seperenambelas).

3. Nyanyian Rohani

Nyanyian Rohani biasanya disebut nyanyian injili, berkembang setelah adanya gerakan penginjilan di akhir abad 19. Tema umum: kesaksian dengan inti pengajaran, dorongan peringatan dan ajakan kepada Kristus, sangat bersifat subjektif - horizontal. Ciri musikal yang menonjol adalah, nilai nada dinominasi not-not $1 / 16$ atau bertitik dan bergaris; irama kuat, tempo cepat, ekspresif sehingga menghasilkan nuansa riang dan bersemangat. Pokok pikiran dalam setiap bait terdapat dalam refrein. Dalam perkembangannya kemudian nyanyian ini lebih dikenal sebagai nyanyian gospel. Penggunaan dalam peribadahan umat pada dasarnya cukup sebanding dengan penggunaan kidung puji-pujian atau himne

\section{Nyanyian Jemaat Dalam Bentuk Baru}

Selain dari ketiga bentuk nyanyian yang sudah diuraikan di atas, sekarang ini beberapa denominasi gereja menggunakan musik jenis dan bentuk baru yang dikenal sebagai nyanyian kontekstual dan nyanyian kontemporer.

a. Nyanyian Kontekstual.

Nyanyian ini tidak terlepas dari gagasan teologis Alkitabiah yang sangat erat hubungannya dengan liturgi ibadah. Melahirkan keberagaman nyanyian dengan alat-alat musik etnis menjadikan

\footnotetext{
${ }^{4}$ H.A. van Dop, Struggling in Hope (Jakarta: BPK Gunung Mulia 1999), 101.
} 
kekayaan musik tradisi lokal sebagai modal berteologi kontekstual yang mencakup semua aspek dalam umat, yaitu: budaya, sosial, bahasa, rohani, teologia, gereja, liturgi, dan musisi. Pikiran bahwa musik gereja bukan hanya milik "Barat" memacu kreasi musisi lokal untuk lebih kreatif dalam menciptakan nyanyian-nyanyian baru yang kontekstual tetapi tetap dengan syair rohani yang alkitabiah. Ciri musik kontekstual ini adalah: unsur musik daerah, original, tidak ada pengaruh musik asing, murni akulturatif. Gaya musik terdiri dari: Western hymn styles atau gaya himne Barat; traditional styles atau gaya tradisional, artinya mengadaptasi melodi asli lokal "grass root" atau komposisi baru dalam keadaan musik masa kini tetapi tetap bercorak asli dengan atau tanpa musik pengiring; syncretistic styles atau lagu rakyat dengan melodi dengan ciri tradisional, diaransemen dengan gaya tradisi harmoni Barat; serta international and contextual styles atau karya inovatif, yang merupakan gabungan konsep musik tradisi dengan teknik komposisi kontemporer, berhubungan dengan budaya lokal. Sedang kaidah musiknya: memakai tangga nada bukan diatonis dalam konsep tradisi Barat, berirama 1, 2, dan 4 ketuk dengan pola ritem yang sering berulangulang. ${ }^{5}$ Upaya kontekstualisasi musik gereja akan sangat terasa relevan dan kontekstual pada saat umat beribadah. Melalui nyanyian pujian yang dilagukan, umat dapat menghayati Injil sekaligus meresapi dan menikmati ritme kehidupannya sehari-hari. ${ }^{6}$ Sekarang ini, nyanyian baru dengan aneka ragam pola lagu serta latar belakang budaya daerah banyak digunakan sebagai nyanyian liturgi dalam ibadah gereja-gereja yang menggunakan buku nyanyian Kidung Jemaat dan Pelengkap Kidung Jemaat terbitan YAMUGER.

b. Nyanyian Rohani Kontemporer

Nyanyian rohani kontemporer berawal pada tahun 1960-an dari sebuah kebaktian penginjilan sekelompok anak muda hippies di negara bagian California. ${ }^{\top}$ Kelompok yang bertobat ini kemudian melanjutkan pelayanan penginjilan ke negara-negara bagian lain di Amerika dan berhasil menjangkau serta melayani kaum muda yang belum mengenal Kristus. Tentu saja dalam perjalanan penginjilan para petobat baru ini, mereka menyertakan nyanyian-nyanyian baru

\footnotetext{
${ }^{5}$ Christian Tamaela, Kontekstualisasi Musik Gereja. Mengadakan Musik Gereja sesuai Musik Tradisi Indonesia. PESPARAWI Pemuda se-Sulawesi Selatan, 2004),5.

${ }^{6}$ Perry Rumengan, Musik Gerejawi Kontekstual Etnik Salah Satu Sarana Evangelisasi Masa Kini Dalam Liturgi Kreatif, (Seminar Musik Gereja STT J 11 September 2012).

${ }^{7}$ Agastya Rama Listya, Ibadah dan Nyanyianj Rohani Kontemporer: Berkat atau Kutuk? (Diskusi Musik Gereja, BU UKSW 2005, 3.
} 
yang lahir secara spontan penuh improvisasi pada saat kebaktian dengan gaya bernyanyi yang "lepas" dan meriah oleh permainan musik yang sangat energik. Kemudian pertumbuhan pesat nyanyian ini terjadi seiring lahirnya industri musik rekaman yang berlabel Kristen. Melalui rekaman yang tersebar dengan cepat, nyanyian kontemporer pun dengan cepatnya merambah ke negara-negara di luar Amerika termasuk Indonesia. Perlawanan dan penolakan akan nyanyian rohani kontemporer sempat gencar, terutama oleh kalangan Lutheran, ${ }^{8}$ yang menganggap nyanyian-nyanyian baru ini sangat kontoversial. Bahkan hingga sekarang pun keberadaan nyanyian rohani kontemporer masih sering dipertentangkan terutama di kalangan gereja-gereja protestan arus utama. Memang ada yang berargumen bahwa nyanyian rohani kontemporer bukan merupakan strategi seseorang atau sekelompok orang agar ibadah terasa lebih kontemporer, tetapi gaya baru itu muncul karena konteks sejarah kebangunan rohani yang khusus. ${ }^{9}$ Dengan syair yang bersifat individual - penggunaan kata "aku" yang dominan fokus pemujaan atau penyembahan hanya pada kemahaberadaan Allah - bukan pada kedaulatan-Nya - dan sukacita yang meluapluap atas keselamatan dan pengampunan dosa yang dimaknai secara emosional, ${ }^{10}$ nyanyian rohani kontemporer terus bertumbuh dan berkembang tanpa dibatasi waktu dan tema ibadah. Nilai musikalnya sendiri tidak berbeda dengan nyanyian rohani, satu hal yang menonjol adalah musik pengiring merupakan iringan lengkap atau full band

\section{Mengenal Syair Musik Gereja}

Nyanyian jemaat, yang terdiri dari Mazmur, Kidung Puji-Pujian, Nyanyian Rohani, Nyanyian Kontekstual, dan Nyanyian Kontemporer, pada dasarnya - apa pun jenis dan bentuknya - adalah puji-pujian umat kapada Sang Pencipta Seberhana Alam, yang penggunaannya disesuaikan dengan tema ibadah yang sedang berlangsung. Dari syair nyanyian dapat diketahui pesan yang terkandung di dalam nyanyian, sehingga kesalahan atau kekeliruan dalam menggunakan nyanyian dapat dihindari. Sedangkan syair dan pesan yang terkandung di dalamnya secara substansial meliputi tiga hal yaitu :

1. Ajaran Alkitab mengenai keselamatan yang mencakup : masa penciptaan, masa penantian Mesias (Adventus), kelahiran Yesus,

\footnotetext{
${ }^{8}$ Lovelace and Rice, Music And Worship In The Church (Abingdon Nasville, 1981), 196.

9 Agastya Rama Listya, 3.

${ }^{10}$ Ibid
} 
kematian, kebangkitan dan kenaikan-Nya, turunnya Roh Kudus, hingga kedatangan-Nya yang kedua kali kelak.

2. Pernyataan keyakinan iman serta hidup kerohanian umat Tuhan yang mencakup : pergumulan, penyerahan diri, kesukacitaan dalam Tuhan, dan kemenangan iman

3. Penginjilan yang mencakup : Pemberitaan Injil keselamatan kepada dunia dan ajakan kepada orang lain untuk menerima Yesus sebagai Juruselamat pribadinya.

\section{PRAKTEK DAN PROSEDUR NYANYIAN JEMAAT}

\section{Buku Nyanyian}

Pada umumnya nyanyian yang digunakan dalam ibadah gereja bersumber dari buku nyanyian. Buku-buku nyanyian yang banyak dan umum dipakai antara lain : Kemenangan Iman (KI), Kumpulan PujiPujian Kristen (KPPK), Kidung Jemaat (KJ), Nyanyian Rohani, Mazmur, Pelengkap Kidung Jemaat (PKJ). Dari semua buku nyanyian di atas, buku nyanyian Kidung Jemaat yang paling lengkap isinya, karena di dalamnya terkandung nyanyian dalam bentuk Mazmur, Kidung Pujipujian/Himne, Nyanyian Rohani, maupun nyanyian-nyanyian kontekstual Asia termasuk Indonesia.

\section{Tematik Nyanyian}

Tematik nyanyian yang tercantum dalam buku nyanyian bermanfaat untuk memudahkan mencari dan mendapatkan nyanyian-nyanyian yang dibutuhkan menurut kepentingan ibadah. Biasanya tematik nyanyian disesuaikan dengan rumpun ibadah yang umum dalam liturgi gereja yaitu: Menghadap Tuhan - Pelayanan Firman - Pengucapan Syukur Pengutusan. Tematik nyanyian secara garis besar mencakup: doa, pujipujian, pengakuan dosa, penyerahan diri, pernyataan iman, pengucapan syukur, berkat, dan sebagainya.

\section{Memilih Nyanyian.}

Dalam memilih dan menetapkan nyanyian yang akan digunakan dalam ibadah, penting untuk memerhatikan beberapa hal:

- Nyanyian harus sesuai dengan tema dan mampu mendukung setiap bagian liturgi

- Syair nyanyian harus mengandung kebenaran teologis

- Syair nyanyian harus selaras dengan melodi

- Nyanyian sudah dikenal dan dikuasai jemaat dengan baik

- Pelajari melodi dan syair nyanyian dengan seksama sebelum menetapkan pilihan terhadap nyanyian baru 
- Baca syair nyanyian bait per bait untuk menentukan bait-bait yang cocok dan sesuai dengan ibadah, tidak ada hukum yang harus menyanyikan semua bait lagu

- Kenali kelompok yang akan dilayani agar nyanyian yang sudah disiapkan tidak salah pilih atau salah "alamat"

- Jalin kerjasama dengan perangkat pendukung ibadah, terutama para pemusik dan penyanyi, buat persiapan dan disiplin sangat penting untuk pelayanan yang layak dan berkenan bagi Tuhan.

\section{PENUTUP}

Banyak orang yang menganggap bahwa nyanyian jemaat dalam ibadah tidak terlalu penting dibandingkan dengan nyanyian paduan suara atau musik lainnya yang ada di gereja. Dengan anggapan bahwa jemaat sudah mengenal, sudah mengetahui, bahkan sudah menguasai lagunya, maka tidak perlu ada persiapan atau pun latihan. Tentu saja ini anggapan yang sangat keliru. Setiap umat hendaknya memahami bahwa nyanyian jemaat yang digunakan dalam rangkaian liturgi ibadah haruslah dipersiapkan, dilatih, dan dipersembahkan dengan sebaikbaiknya.

Sikap peduli nyanyian jemaat perlu dipertahankan, pemeliharaan buku nyanyian harus terus menerus dilakukan. Memang harus diakui, kesalahan seringkali terjadi seperti: penggunaan lagu dari minggu ke minggu itu-itu saja - tidak sesuai dengan tematik ibadah, kurang variatif, selera siapa (?) - penempatan nyanyian tidak sesuai dengan rumpun ibadah - lagu tidak sesuai dengan kalender gereja, tidak sesuai dengan doktrin gereja - tetapi semua itu merupakan hal yang masih bisa dihindari bahkan diperbaiki demi mencapai kesempurnaan.

Akhirnya, selama Gereja Tuhan masih kokoh berdiri, nyanyian apa pun bentuk dan karakternya, tetap dan akan terus berkumandang hanya untuk memuji kebesaran dan kemuliaan Tuhan. Terpujilah Tuhan atas segala kebesaran dan kekuasaan-Nya.

\section{KEPUSTAKAAN}

Buku-buku

Lovelace and Rice, Music And Worship In The Church. Abingdon Nasville, 1981.

Osbeck, Kenneth W., The Ministry of Music. Grand Rapids, Michigan Kregel Publications, 1992. 
Van Dop, H.A., Menggubah Nyanyian Jemaat Jakarta: BPK Gunung Mulia, 1984

Struggling in Hope; Jakarta: BPK Gunung Mulia, 1999

Diktat

Jurusan Musik Gerejawi STTJ Perkembangan Musik Gerejawi dari Masa ke Masa

Rohani Siahaan., Dasar Musik Gereja - dari berbagai sumber Makalah

Agastya Rama Listya, Ibadah dan Nyanyianj Rohani Kontemporer: Berkat atau Kutuk? Diskusi Musik Gereja, BU UKSW, 18 Mei 2005

Christian I Tamaela., Kontekstualisasi Musik Gereja. Mengadakan Musik Gereja sesuai Musik Tradisi Indonesia. PESPARAWI Pemuda seSulawesi Selatan, 2004

Perry Rumengan, Musik Gerejawi Kontekstual Etnik Salah Satu Sarana Evangelisasi Masa Kini Dalam Liturgi Kreatif, Seminar Musik Gereja

Catatan: STT J 11 September 2012.

1. H.A.van Dop, seorang penggubah lagu-lagu liturgi gereja, salah seorang pendiri Yayasan Musik Gereja (YAMUGER),

berkebangsaan Belanda dan pernah menetap di Indonesia kurang lebih tiga dekade.

2. Lovelace and Rice (1981:154) : seharusnya gereja-gereja masa kini pun memakai ketiga bentuk nyanyian tersebut dalam ibadahnya, sayang sekali hal ini tidak terjadi karena banyak gereja sekarang dalam ibadahnya lebih banyak menggunakan nyanyian rohani dan nyanyian kontemporer.

3. Dari percakapan dengan beberapa musisi gereja maupun hambahamba Tuhan, faktor musikal ini menjadi alasan kuat untuk tidak memakai Mazmur, karena dianggap sulit untuk menyanyikan nada-nadanya yang kurang melodis, di samping sdm yang tidak tersedia dan bersedia untuk melatihnya, sehingga Mazmur semakin kurang diminati (?)

4. H.A. van Dop, Oukumene dalam Nyanyian Gereja; Struggling in Hope; Jakarta: BPK, 1999 - beberapa gereja protestan masih setia menggunakan nyanyian Mazmur dalam liturgi ibadahnya.

5. Ciri-ciri ini merupakan otokritik dari pemikiran para lintas denominasi yang pro-kontra atas nyanyian rohani kontemporer. 